\title{
Towards a hydrological classification of European soils: preliminary test of its predictive power for the base flow index using river discharge data
}

\author{
M. K. Schneider ${ }^{1}$, F. Brunner ${ }^{1}$, J. M. Hollis ${ }^{2}$, and C. Stamm ${ }^{1}$ \\ ${ }^{1}$ Swiss Federal Institute of Aquatic Science and Technology, Eawag, 8600 Dübendorf, Switzerland \\ ${ }^{2}$ Independent consultant, 58 St.Annes Rd., London Colney, St. Albans, AL2 1LJ, UK
}

Received: 29 March 2007 - Published in Hydrol. Earth Syst. Sci. Discuss.: 16 April 2007

Revised: 8 August 2007 - Accepted: 15 August 2007 - Published: 20 August 2007

\begin{abstract}
Predicting discharge in ungauged catchments or contaminant movement through soil requires knowledge of the distribution and spatial heterogeneity of hydrological soil properties.

Because hydrological soil information is not available at a European scale, we reclassified the Soil Geographical Database of Europe (SGDBE) at 1:1 million in a hydrological manner by adopting the Hydrology Of Soil Types (HOST) system developed in the UK. The HOST classification describes dominant pathways of water movement through soil and was related to the base flow index (BFI) of a catchment (the long-term proportion of base flow on total stream flow). In the original UK study, a linear regression of the coverage of HOST classes in a catchment explained 79\% of BFI variability.

We found that a hydrological soil classification can be built based on the information present in the SGDBE. The reclassified SGDBE and the regression coefficients from the original UK study were used to predict BFIs for 103 catchments spread throughout Europe. The predicted BFI explained around $65 \%$ of the variability in measured BFI in catchments in Northern Europe, but the explained variance decreased from North to South. We therefore estimated new regression coefficients from the European discharge data and found that these were qualitatively similar to the original estimates from the UK. This suggests little variation across Europe in the hydrological effect of particular HOST classes, but decreasing influence of soil on BFI towards Southern Europe.
\end{abstract}

Our preliminary study showed that pedological information is useful for characterising soil hydrology within Europe and the long-term discharge regime of catchments in Northern Europe. Based on these results, we draft a roadmap for a refined hydrological classification of European soils.

Correspondence to: M. K. Schneider

(manuel.schneider@eawag.ch)

\section{Introduction}

Water movement through soil is a primary determinant of discharge dynamics in a catchment (Boorman et al., 1995; Beven, 2001; McDonnell, 2003). Accordingly, soil hydrology is an essential prerequisite for understanding the hydrology of a basin. Such knowledge is crucial for the prediction of discharge response in ungauged catchments (Sivapalan, 2003; McDonnell and Woods, 2004) and the evaluation of effects of changing environmental conditions such as land use and climate (Kirchner, 2006).

The relevance of soil hydrology goes well beyond the prediction of the behaviour of ungauged basins. An example for this comes from monitoring herbicide losses in watersheds, which was found to depend strongly on hydrological soil properties (Blanchard and Lerch, 2000). Field experiments on herbicide losses in small agricultural catchments have shown that site properties crucially affect the proportion of applied substances ending up in the receiving brook (Leu et al., 2004). These findings are in line with the variable source area concept, that storm runoff originates from a small part of a catchment only (Hewlett and Hibbert, 1967). Assessing the environmental impact of agricultural production thus requires knowledge on the hydrological response of soil units, their distribution and spatial heterogeneity. Such information is most often patchy, i.e. only available for small, incoherent areas, e.g. experimental catchments. This limited data availability is often in conflict with the tendency towards multi-national and global standards and procedures in assessing environmental risks of chemical substances used in agriculture (Schneider et al., 2007), which require information on soil hydrology at comparable scales.

Although pedologists started to compile and harmonise European soil data as early as 1974 , information on the hydrological behaviour of soils at the European scale is still widely lacking. The most recent and most comprehensive source of soil information at a European scale is the

Published by Copernicus Publications on behalf of the European Geosciences Union. 
European Soil Database at 1:1 million scale. It consits of the polygons of the Soil Geographical Database of Europe (SGDBE, King et al., 1994) with associated primary pedological attributes as well as of additional characteristics derived from pedo-transfer rules developed by expert knowledge. It also contains databases of soil profile descriptions and analyses, which have been connected to many of the soil units in the map (Hollis et al., 2006), as well as a database of hydraulic properties called HYPRES (Wösten et al., 1999). HYPRES contains a set of derived pedo-transfer functions for predicting Mualem-van Genuchten parameters from SGDBE attributes on soil particle size fractions, organic carbon content and bulk density (Wösten et al., 1999). There is a need to complement HYPRES by a more conceptual interpretation of soil hydrological characteristics from existing pedological information at a European level.

Soil properties and catchment response could be related, for example, through a hydrological model using the hydraulic parameters estimated by HYPRES (Wösten et al., 1999). However, the HYPRES pedo-transfer functions may give unsatisfactory predictions of soil hydrological characteristics because additional pedological information (e.g. on impermeable layers) and boundary conditions (e.g. parent material) are not taken into account (Lin et al., 2006). A completely different concept is the Curve Number Model (Soil Conservation Service, 1972), which estimates direct runoff from rainfall using information on the hydrological soil group, land cover and antecedent moisture conditions. In the United States, the soil hydrologic groups were determined directly during soil survey, but they are not available in the SGDBE. On top, with only four soil hydrologic groups, each of which can encompass different mechanisms of generating runoff, this concept is limited.

A more holistic approach for the description of soil hydrology was developed in the United Kingdom by Boorman et al. (1995). Their system of Hydrology Of Soil Types (HOST) classifies soils according to conceptual models representing the dominant features controlling water movement through soil and hence the mean residence time of water in soils. This approach to classify soil hydrologic properties was quantitatively linked to hydrology by deriving Base Flow Indices (BFI) for 575 catchments in the UK. The Base Flow Index (BFI) corresponds to the long-term average proportion of flow that occurs as base flow (Institute of Hydrology, 1980). It provides a measure of the overall discharge responsiveness of a catchment, even if it is derived, as in this study, from the hydrograph alone with little physical underpinning. The BFI may not be result of soil hydrological conditions alone, but also of topography and/or climate. However, its simplicity makes it an attractive concept for evaluating a hydrological soil classification at a European scale.

Boorman et al. (1995) used multiple linear regression to estimate a regression coefficient for each of the 29 HOST classes and called them BFI coefficients. These coefficients describe the effect of a particular HOST class on the BFI and can be used for BFI prediction by simple weighting with the fraction of the class in the catchment. Boorman et al. (1995) found that their regression, i.e. the coverage of HOST classes in a catchment, explained $79 \%$ of the variability in the measured BFI. Including topography, land cover or climate did not increase the explained variance and it was concluded that, in the UK at least, these environmental characteristics were already largely reflected in the HOST classes. HOST has been successfully used to predict catchment response at the small to mesoscale, in catchments of 10 to $1000 \mathrm{~km}^{2}$ (Dunn and Lilly, 2001; Maréchal and Holman, 2005; Soulsby et al., 2006b). A process-based soil classification such as HOST may thus integrate regional climatic and topographic variation and have the potential to be extendable to a European scale.

Outside the UK, Haberlandt et al. (2001) used slope, topographic index, hydraulic conductivity and precipitation to predict BFI patterns in the Elbe River Basin and Lacey and Grayson (1998) related the BFI of catchments in Victoria (Australia) to altitude, forest coverage and precipitation amongst other parameters. The two studies found negative (Haberlandt et al., 2001) and positive (Lacey and Grayson, 1998) correlations between precipitation and the BFI, suggesting that effects of climatic parameters on BFI vary regionally. It might thus be important to consider climate and topography in an extrapolation of HOST beyond the UK.

In this study, we evaluated whether the SGDBE, as the most comprehensive harmonised source of pedological information at a European scale, could be reclassified into HOST classes. We then investigated how the soil properties conceptualised by HOST affected the BFI of a selection of small European catchments. This was done in a two-step approach:

1. We predicted BFI values for the evaluated catchments using the regression coefficients from the original HOST study in the UK by Boorman et al. (1995).

2. We estimated new regression coefficients from the discharge data of the European catchments and compared them to the estimates of Boorman et al. (1995).

By doing so, we explored regional differences in the driving factors of catchment response at the European scale and the feasibility of a hydrological classification of European soils. In this sense, we consider our work as an important first step towards an improved hydrological interpretation of European soil information.

\section{Data preparation and analysis}

\subsection{Reclassification of SGDBE into HOST classes}

The reclassification was performed using a logical decision tree, which is available for download as supplementary information SI-1 (http://www.hydrol-earth-systsci.net/11/1501/2007/hess-11-1501-2007-supplement.pdf). 
Table 1. Scheme used to reclassify the Soil Geographical Database of Europe (SGDBE) into HOST classes

\begin{tabular}{|c|c|c|c|c|c|c|c|c|}
\hline \multicolumn{3}{|c|}{ PHYSICAL SUBSETTINGS } & \multicolumn{4}{|c|}{ MINERAL SOILS } & \multirow{2}{*}{\multicolumn{2}{|c|}{$\begin{array}{c}\text { PEAT SOILS } \\
\begin{array}{c}\text { TEXT1 }=9 \mid \\
(T E X T 1=0 \& \\
T E X T 2=9)\end{array}\end{array}$}} \\
\hline & Substrate hydrogeology & $\begin{array}{l}\text { Ground- } \\
\text { water or } \\
\text { aquifer }\end{array}$ & $\begin{array}{c}\text { No impermeable or } \\
\text { gleyed layer within } \\
100 \mathrm{~cm} \\
I L=0,1 \mid D G H=V\end{array}$ & $\begin{array}{l}\text { Imp } \\
\text { gleyec } \\
I L=2,\end{array}$ & $\begin{array}{l}\text { able or } \\
\text { r at } 40- \\
\text { m } \\
G H=M\end{array}$ & $\mid \begin{array}{c}\text { Gleyed layer within } \\
40 \mathrm{~cm} \\
\text { DGH }=\boldsymbol{S}\end{array}$ & & \\
\hline i. 1 & $\begin{array}{l}\text { Weakly consolidated, microporous, } \\
\text { by-pass flow uncommon (Chalk) }\end{array}$ & \multirow{6}{*}{$\begin{array}{c}\text { Normally } \\
\text { present and at } \\
>2 \mathrm{~m} \text { depth } \\
W R=0,1,2,3\end{array}$} & 1 & \multirow{6}{*}{\multicolumn{2}{|c|}{13}} & \multirow{6}{*}{14} & \multirow{6}{*}{\multicolumn{2}{|c|}{15}} \\
\hline i. 2 & $\begin{array}{l}\text { Weakly consolidated, microporous, } \\
\text { by-pass flow uncommon (Limestone) }\end{array}$ & & 2 & & & & & \\
\hline i. 3 & $\begin{array}{l}\text { Weakly consolidated, macroporous, } \\
\text { by-pass flow uncommon }\end{array}$ & & 3 & & & & & \\
\hline i.4 & $\begin{array}{l}\text { Strongly consolidated, non or slightly } \\
\text { porous, by-pass flow common }\end{array}$ & & 4 & & & & & \\
\hline i.5 & $\begin{array}{l}\text { Unconsolidated, macroporous, } \\
\text { by-pass flow very uncommon }\end{array}$ & & 5 & & & & & \\
\hline i. 6 & $\begin{array}{l}\text { Unconsolidated, microporous, } \\
\text { by-pass flow common }\end{array}$ & & 6 & & & & & \\
\hline ii. 1 & $\begin{array}{l}\text { Unconsolidated, macroporous, } \\
\text { by-pass flow very uncommon }\end{array}$ & \multirow{2}{*}{$\begin{array}{c}\text { Normally } \\
\text { present and at } \\
\leq 2 \mathrm{~m} \text { depth } \\
W R=4 \mid \mathbf{H G}=2\end{array}$} & \multicolumn{3}{|c|}{7} & \multirow{2}{*}{10} & $\begin{array}{ll}\text { drained } \\
22\end{array}$ & $\underset{2)}{\underset{2 n}{u}}$ \\
\hline ii. 2 & $\begin{array}{l}\text { Unconsolidated, microporous, } \\
\text { by-pass flow common }\end{array}$ & & \multicolumn{3}{|c|}{8} & & 11 & 12 \\
\hline \multirow{2}{*}{ iii.1 } & \multirow{2}{*}{ Slowly permeable } & \multirow{5}{*}{$\begin{array}{l}\text { No significant } \\
\text { groundwater } \\
\text { or aquifer }\end{array}$} & \multirow{2}{*}{16} & coarse & fine $^{1)}$ & \multirow{2}{*}{24} & \multirow{2}{*}{\multicolumn{2}{|c|}{26}} \\
\hline & & & & 18 & 21 & & & \\
\hline iii. 2 & Impermeable (hard) & & \multirow{2}{*}{17} & 19 & 22 & \multirow{2}{*}{25} & \multirow{2}{*}{\multicolumn{2}{|c|}{27}} \\
\hline iii.3 & Impermeable (soft) & & & 20 & 23 & & & \\
\hline iii.4 & Peat & & & & & & & 29 \\
\hline
\end{tabular}

SGDBE attributes used for reclassification: WR: Water Regime, HG: Hydrological Class, IL: Depth to impermeable layer, DGH: Depth to gleyed layer, TEXT1: Dominant surface textural class, TEXT2: Secondary surface textural class.

1 Texture as a proxy for soil water storage capacity. Fine: TEXT1 $>=4 \mid$ TEXT2 $>=4$. Coarse: NOT fine

2 Agricultural use as a proxy for drained/undrained. Drained: USE1=1, 3, 6, 7, 12 to 17. Undrained: NOT drained. USE1 is describing dominant land use within an STU. Logical operators: \&: and; |: or.

We used the SGDBE, version 3.2.8.0, on which further information can be found at http://eusoils.jrc.it. The SGDBE is built upon Soil Mapping Units (SMU), which are georeferenced and composed of one or more Soil Type Units (STU). Each STU is described by attributes specifying the nature and properties of the soils, for example parent material, dominant surface texture class, water regime etc. The percentage in a SMU that is covered by each STU is given, but not their location. Hence, an SMU is the smallest available spatial object, but the availability of multiple STUs improves the quantification of pedological information. The SGDBE was produced at 1:1 million scale by harmonising and simplifying available national soil data (King et al., 1994). This process was initiated during the 1970's and a paper map covering the twelve EC Member States at that time, was published in 1985 (CEC, 1985). The map was digitized in the late 1980's and subsequent work during the 1990's and early 2000's extended the number of countries included and also the attribute information used to characterize each STU. England and Wales was one of the original twelve countries covered by the 1985 map. The digitized polygon data for the two countries is based on this map and the soil information available during its 1970's compilation. It thus does not reflect the information compiled for the 1:250 000 National Soil Map published in 1985 although the STU attribute data was updated to include this information and a very limited number of polygon boundaries were modified.

The reclassification aimed at reflecting the original HOST system (Boorman et al., 1995) as close as possible. Table 1 shows the resulting scheme which is very similar to the original HOST system with a few exceptions outlined below. In the first step of reclassification, substrate hydrogeology and the presence of groundwater or aquifers were used to define twelve physical subsettings (Table 1, i.1 to iii.4). Substrate hydrogeology was derived from the parent material of each STU in the SGDBE, guided by Boorman et al. (1995: Tables 3.1 to 3.3) and expert judgement. The presence of aquifers or groundwater near the surface was more difficult to represent because no direct information was available in the SGDBE. Hence, SGDBE attributes "Water Regime" (WR) and "Hydrological Class" (HG) were used. WR describes whether a soil is wet within a certain depth and for how many months per year. WR is not a pure soil attribute but incorporates perceptions of climate and topography. HG is derived by a pedotransfer rule from information of soil type, altitude and permeability. Soils in WR 4 (wet within $40 \mathrm{~cm}$ depth for over 11 months) were attributed to physical setting ii), other 
WR classes $(0,1,2$ and 3$)$ were attributed to physical setting i). HG class 2 stands for "lowland soil affected by groundwater, seasonally or permanently wet, or artificially drained" and was found to be representative for physical setting ii) by comparison with the original HOST map by Boorman et al. (1995).

In the second step, STUs were further classified according to permeability and the presence of peat. Again, not all attributes used for HOST were present in the SGDBE and it was necessary to use other SGDBE attributes as proxies. As an indicator of impermeability or gleying, attributes "Presence of an impermeable layer within a certain depth" (IL) and "Depth to a gleyed horizon" (DGH) were used (Table 1). The original HOST classification used the integrated air capacity to further separate soils on impermeable or slowly permeable substrate into groups with large or small soil water storage capacities. Integrated air capacity is a measure of the soil macroporosity defined as the volume of pores in the soil which are greater than $60 \mu \mathrm{m}$ and was derived from soil profile data (Hollis and Woods, 1989). Since integrated air capacity was not available in SGDBE, a separation was based upon dominant or secondary surface textural class (Table 1, classes 18 to 21). Peat soils were determined by considering the dominant texture class, which contains a separate peat class, and, where dominant texture information was missing, the secondary texture class. If the parent material was reported as "organic materials", soils were directly assigned to class 29 (Table 1). Peat soils with shallow aquifer or groundwater were divided according to whether a peat soil is drained or not (Table 1, classes 11 and 12). Since there was no such information in SGDBE, all peat soils with agricultural use were assumed to be drained.

This procedure permitted to almost fully reproduce the HOST concept on the basis of SGDBE and pedotransfer attributes. There remained 3 differences: (i) Eroded peat and raw peat (classes 28 and 29 in Boorman et al. (1995)) were not distinguishable and, thus, merged into one group called Peat (Table 1, class 29). (ii) In the original HOST classification, soils with a gleyed layer within $40 \mathrm{~cm}$ and a shallow aquifer were subdivided on the basis of different lateral saturated hydraulic conductivity (classes 9 and 10 in, Boorman et al., 1995). In the European soil map, no attribute to establish such a differentiation was available and the two classes were aggregated to class 10 (Table 1). (iii) Due to wider range of soils in Europe, classes 17, 25 and 27 were extended to cover physical subsettings iii.2) and iii.3), whereas in the UK, these combinations are not present and no HOST classes were defined (Boorman et al., 1995).

The original HOST classification and the reclassified SGDBE were qualitatively compared in England and Wales based on the original and the reclassified map (Figs. 1a, b). The original HOST map at $1 \mathrm{~km}^{2}$ grid size was prepared from the 1:250000 National Soil Map by identifying all soil map units in each $\mathrm{km}^{2}$ and then applying the HOST classification as the sum of the percentages across all map units (Boorman et al. 1995). A quantitative comparison was performed using an ad-hoc measure on the basis of the SMU, which are the smallest spatial units of the SGDBE with unique soil information (King et al., 1994). For each SMU, the fractions of all HOST classes were extracted either directly from the original HOST map or, in the case of the reclassified SGDBE, using the percentage of STUs in the SMU. The extracted fractions were then multiplied by the area of the SMU. These values represent observations of the coverage of each HOST class in the two maps and would lay on a 1:1 line in case of a perfect reclassification. Normalized residuals from the 1:1 line $\left(\mathrm{NR}_{1: 1}\right)$ were calculated for each HOST class as:

$$
N R_{1: 1}=\frac{\sum_{i}\left|F_{i}^{o}-F_{i}^{r}\right| \cdot A_{i}}{\sum_{i}\left(F_{i}^{o}+F_{i}^{r}\right) \cdot A_{i}}
$$

where $F_{i}^{o}$ and $F_{i}^{r}$ are the fraction of a particular HOST class in the $i$-th SMU in the original map and the reclassified SGDBE, respectively, $A_{i}$ is the area covered by the $i$-th SMU. NR $\mathrm{N}_{1: 1}$ are 0 in case of a perfect match between the two maps and 1 in case of complete disagreement.

\subsection{Preparation of discharge data}

Data on mean daily discharge in European catchments was obtained from the Global Runoff Data Centre (GRDC). Primary selection criteria for the catchments used in this study were a catchment size smaller than $5000 \mathrm{~km}^{2}$, a spread over Europe as uniform as possible and the coverage of a large range of soil types. In a more detailed evaluation during the study, also catchments with lakes or artificial flow corrections and a high proportion of urban area were excluded. At this stage, no restriction was set on the number of available record years, which ranged from 3 to 114 years.

Long-term BFIs were calculated as the ratio of summed base flow to summed total discharge in a catchment. The base flow was obtained using the smoothed minima method as described by the Institute of Hydrology (1980). The hydrograph was separated into blocks of five days and the minimum discharge was determined for each block. If the minimum discharge of a block was smaller than $90 \%$ of the minima in the preceding and subsequent block, it was considered a turning point. The daily base flow was determined as the smaller value of the linear interpolation between turning points and the actual discharge. Missing values were treated slightly different to the Institute of Hydrology (1980). To avoid bias from incomplete annual data, runoff data of years with more than three consecutive weeks of missing data were removed from the analysis. Additionally, gaps smaller than three weeks were linearly interpolated for the determination of turning points, but excluded for the final summation of base flow. 
a)

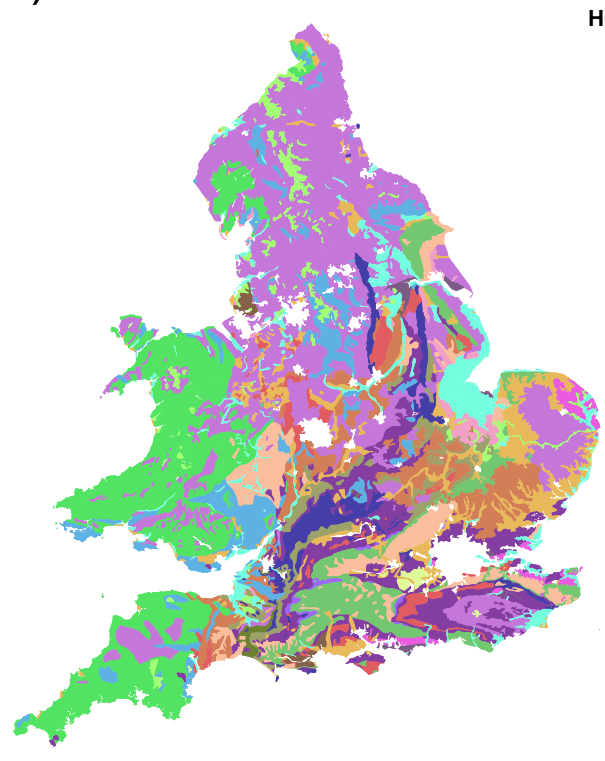

b)

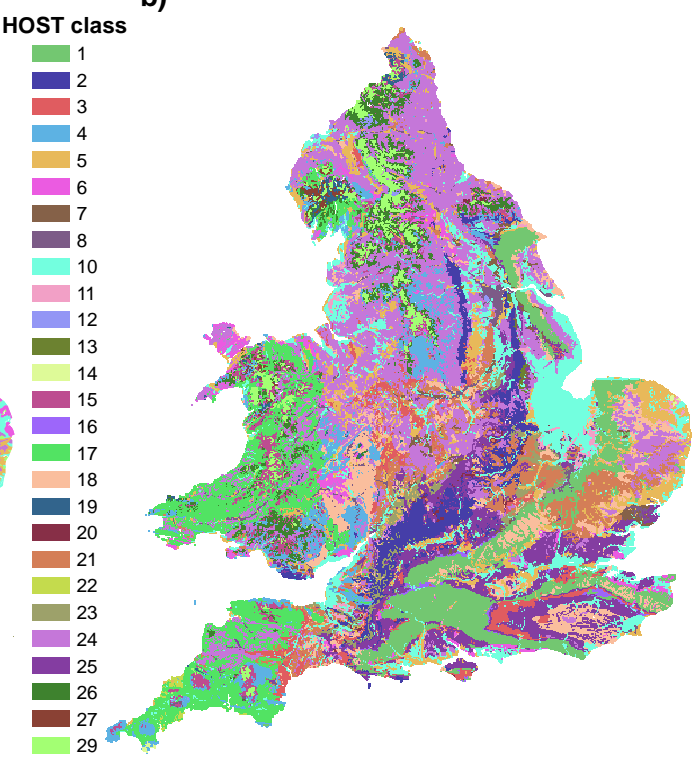

Fig. 1. Coverage of dominant HOST classes in England and Wales (a) as reclassified from the Soil Geographical Database of Europe (SGDBE) and (b) in comparison to the original HOST map. Colours for each HOST class are given in the legend. Gaps in the reclassified SGDBE are due to missing information for urban areas. Copyrights: SGDBE polygons are copyright of the Commission of the European Community, the HOST map is copyright of National Soil Resources Institute, Cranfield University, UK and the Centre for Ecology \& Hydrology, Swindon, UK.

\subsection{Delineation and characterisation of catchments}

To relate the BFI to catchment properties, the catchment boundaries had to be determined. We used the coordinates of the gauging station given in the GRDC database and a digital elevation model (DEM) with $90 \mathrm{~m}$ resolution, obtained from the Shuttle Radar Topography Mission (Void-filled seamless SRTM data V2, 2005, International Centre for Tropical Agriculture, available from http://srtm.csi.cgiar.org/). After filling sinks in the DEM, flow direction was calculated using the single flow direction algorithm (O'Callaghan and Mark, 1984) and accumulated thereafter using ArcGIS 9.1 (ESRI, Redlands, USA). No stream burning was performed, because data was not available at the required quality on a European scale. Since the calculated river network and especially the coordinates of gauging stations in the GRDC database were not always precise enough, the flow accumulation layer and the gauging station did often not coincide. For each catchment, up to three potential gauging positions within a distance of $1.5 \mathrm{~km}$ to the original position were evaluated by calculating the area of all cells lying upstream. The position was selected, at which the upstream area was closest to the area reported by GRDC. If the two areas deviated by more than $5 \%$ for all three positions, the catchment was excluded from further analysis. This criterion reduced the number of catchments from 229 to 103 and was the most important restriction on the use of the GRDC data. A list with the catchments used in the analysis is given as supplementary information SI-2. In order to analyze the influence of topography on the BFI, mean slope, mean altitude, mean topographic index were calculated for each of the catchments based on the SRTM DEM. The topographic index (TI) was calculated for each $90 \mathrm{~m}$ grid cell as

$T I=\ln \left(\frac{a}{\tan \beta}\right)$

where $a$ is the area draining into the cell and $\beta$ the slope of the cell in degrees. The index represents the propensity of each cell to become saturated and act as a source area for surface runoff. Mean values were calculated from all cells in a catchment. High mean values of the index occur in catchments with gentle slopes and/or large flat areas and a simple drainage structure; low mean values occur in catchments with pronounced topography and a highly branched drainage system. The effect of climate was assessed using global data on mean annual precipitation sum and the precipitation amount per wet day (New et al., 2002). Details on the evaluated explanatory variables are provided as supplementary information SI-3. 
Table 2. Percentage coverage of HOST classes in England and Wales in the reclassified Soil Geographical Database of Europe (SGDBE) as compared to the original HOST map with associated normalised residuals and percentage coverage of HOST classes in the reclassified SGDBE in Europe and in the 103 catchments.

\begin{tabular}{|c|c|c|c|c|c|}
\hline \multirow{2}{*}{$\begin{array}{l}\text { HOST } \\
\text { class }\end{array}$} & \multicolumn{2}{|c|}{ Coverage in England and Wales } & \multirow{2}{*}{$\begin{array}{l}\text { Normalised residuals } \\
\text { from the } 1: 1 \text { line }\left(\mathrm{NR}_{1: 1}\right)\end{array}$} & \multicolumn{2}{|c|}{ Coverage of reclassified SGDBE } \\
\hline & $\begin{array}{l}\text { reclassified } \\
\text { SGDBE }\end{array}$ & $\begin{array}{l}\text { original } \\
\text { HOST }\end{array}$ & & in Europe & in 103 catchments \\
\hline 1 & 4.38 & 6.97 & 0.26 & 0.81 & 1.16 \\
\hline 2 & 2.37 & 3.49 & 0.30 & 8.55 & 10.32 \\
\hline 3 & 3.98 & 2.60 & 0.65 & 4.83 & 4.87 \\
\hline 4 & 5.34 & 5.19 & 0.67 & 2.07 & 2.53 \\
\hline 5 & 4.90 & 5.80 & 0.59 & 4.13 & 4.38 \\
\hline 6 & 3.28 & 2.81 & 0.70 & 7.19 & 4.51 \\
\hline 7 & 0.60 & 1.34 & 0.75 & 0.81 & 0.37 \\
\hline 8 & 1.17 & 2.49 & 0.53 & 8.17 & 4.42 \\
\hline 10 & 7.01 & 9.38 & 0.41 & 3.85 & 1.47 \\
\hline 11 & 0.64 & 0.92 & 0.84 & 0.11 & 0.05 \\
\hline 12 & 0.00 & 0.24 & 1.00 & 0.00 & 0.00 \\
\hline 13 & 1.75 & 0.58 & 0.94 & 3.59 & 4.71 \\
\hline 14 & 0.71 & 0.04 & 0.99 & 1.95 & 2.25 \\
\hline 15 & 0.01 & 2.72 & 0.99 & 0.36 & 0.08 \\
\hline 16 & 0.67 & 0.40 & 0.91 & 14.66 & 7.96 \\
\hline 17 & 11.55 & 7.23 & 0.40 & 17.55 & 23.21 \\
\hline 18 & 6.11 & 6.90 & 0.48 & 6.26 & 4.49 \\
\hline 19 & 0.75 & 0.37 & 0.79 & 1.77 & 1.47 \\
\hline 20 & 0.84 & 1.10 & 0.45 & 0.08 & 0.19 \\
\hline 21 & 5.42 & 6.35 & 0.39 & 1.44 & 3.46 \\
\hline 22 & 0.00 & 1.06 & 1.00 & 0.26 & 0.19 \\
\hline 23 & 2.31 & 2.10 & 0.30 & 0.26 & 0.4 \\
\hline 24 & 23.32 & 17.44 & 0.30 & 3.31 & 8.06 \\
\hline 25 & 8.40 & 5.98 & 0.39 & 0.94 & 3.31 \\
\hline 26 & 0.15 & 3.52 & 0.92 & 0.43 & 0.17 \\
\hline 27 & 1.01 & 0.29 & 0.67 & 0.71 & 2.22 \\
\hline 29 & 2.81 & 2.67 & 0.34 & 4.79 & 3.79 \\
\hline
\end{tabular}

2.4 Prediction of BFI based on original UK regression coefficients

In the first step of our evaluation, we predicted BFIs for the evaluated catchments based on the reclassified SGDBE and the regression coefficients estimated to each HOST class based on 575 catchments in the UK (Boorman et al., 1995, Table 3.8). A BFI value for each catchment was calculated as

$\mathrm{BFI}=\sum_{i=1}^{n} a_{i} F_{i}$

where $a_{i}$ is the regression coefficient of HOST class $i$ in the catchment, $F_{i}$ is the fraction for class $i$ and $n$ is the number of HOST classes. For HOST classes 10 and 29, which were aggregated from the original classes 9, 10 and 28, 29, respectively, a weighted average coefficient was calculated based on the UK coverage of the original classes. This led to a regression coefficient $a$ of 0.654 for class 10 and of 0.259 for class 29 .

2.5 Estimation of regression coefficients based on discharge data of European catchments

In the second step of the evaluation, we estimated new regression coefficients for each HOST class from the measured BFIs derived from the discharge data of the studied catchments. This was done by applying Eq. (3) in a multiple linear regression with measured BFI as target variable and HOST class fractions $F$ as explanatory variables. In order to avoid estimations of regression coefficients outside the permissible range for the BFI of 0 and 1, Fisher's $z$ transformation was used (Haberlandt et al., 2001). First, a value $z$ was calculated from the measured BFI as

$z=\frac{1}{2} \ln \left(\frac{\mathrm{BFI}}{1-\mathrm{BFI}}\right)$ 


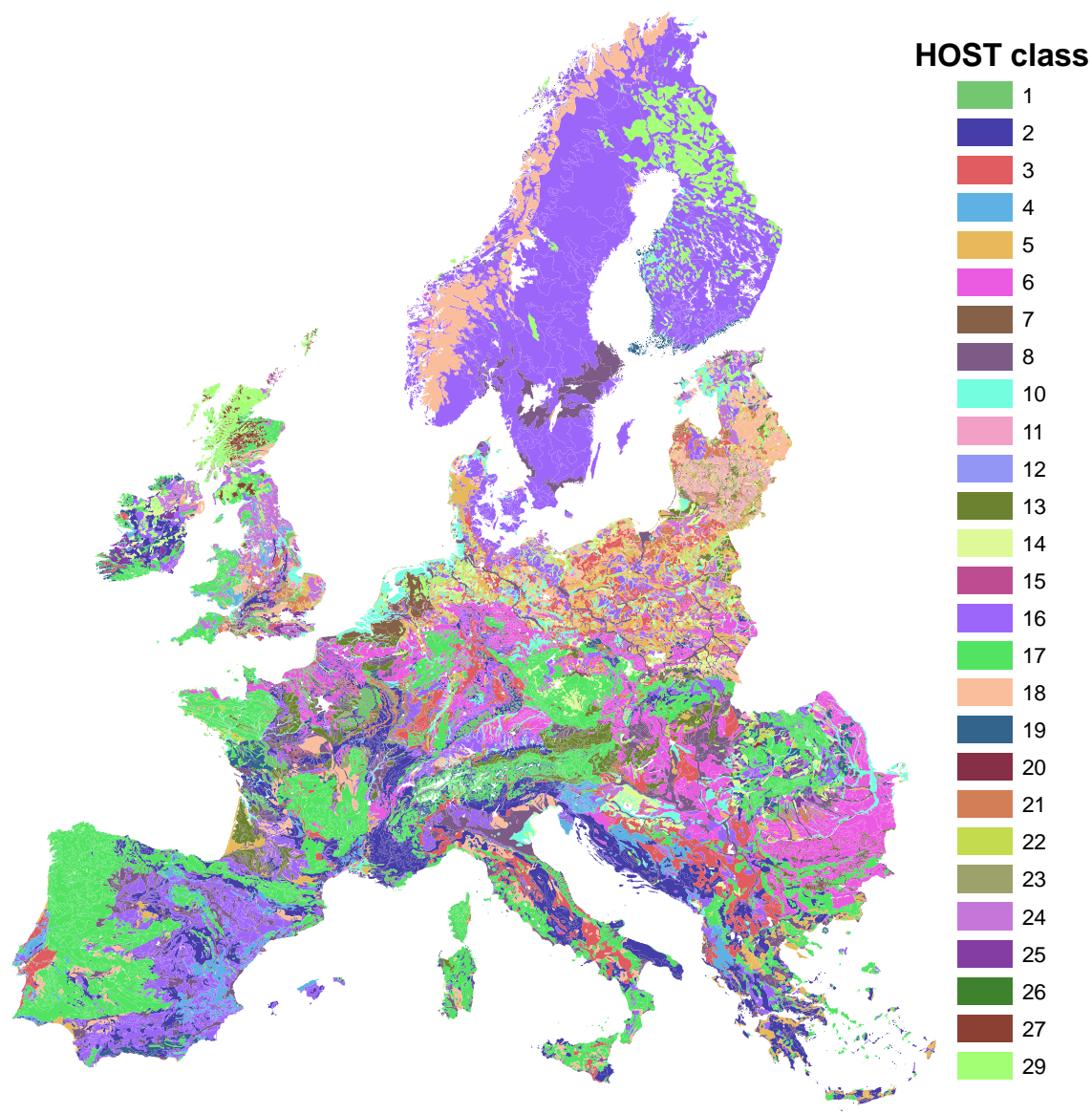

Fig. 2. Soil Geographical Database of Europe (SGDBE) reclassified into HOST classes. Colours for each HOST class are identical to Fig. 1. SGDBE polygons are copyright of the Commission of the European Community.

The multiple linear regression was performed with $z$ as dependant variable and the resulting regression coefficients $a_{z}$ were then back-transformed into regression coefficients $a$ between 0 and 1 by

$a=\frac{1}{2}\left(\frac{\exp \left(2 a_{z}\right)-1}{\exp \left(2 a_{z}\right)+1}\right)+0.5$

Not all classes had equal coverage in the analysed catchments and the estimated coefficients had different support. Therefore, classes with very small coverage were excluded. Akaike's information criterion (AIC) was used to select only those classes which importantly improved the goodness of fit of the classification to the data. AIC penalises the goodness of fit with the complexity of the classification (i.e. the number of classes) and was used to optimize the regression model using the function step in R 2.4.0 (R Development Core Team, 2006). Classes which did not improve AIC when in the model were step-wise excluded. The remaining classes were summed up and set to $100 \%$ to calculate the BFI. As a consequence, one catchment lost more than $60 \%$ of soil information and was excluded from further calculations.

\section{Results}

3.1 Performance of the reclassified SGDBE for England and Wales

For England and Wales, the reclassified SGDBE (Fig. 1a) agreed qualitatively well with the original HOST classification (Fig. 1b). Especially, the classes with a high coverage (e.g. classes 17, 18 and 24 on slowly permeable or inpermeable substrate) and those based on distinct geological features (e.g. class 1 on chalk and class 2 on limestone) were generally well reproduced. The coarser resolution of the SGDBE of 1:1 million led to small-scale variability being lost. For example, HOST classes 7, 8 and 10, which 


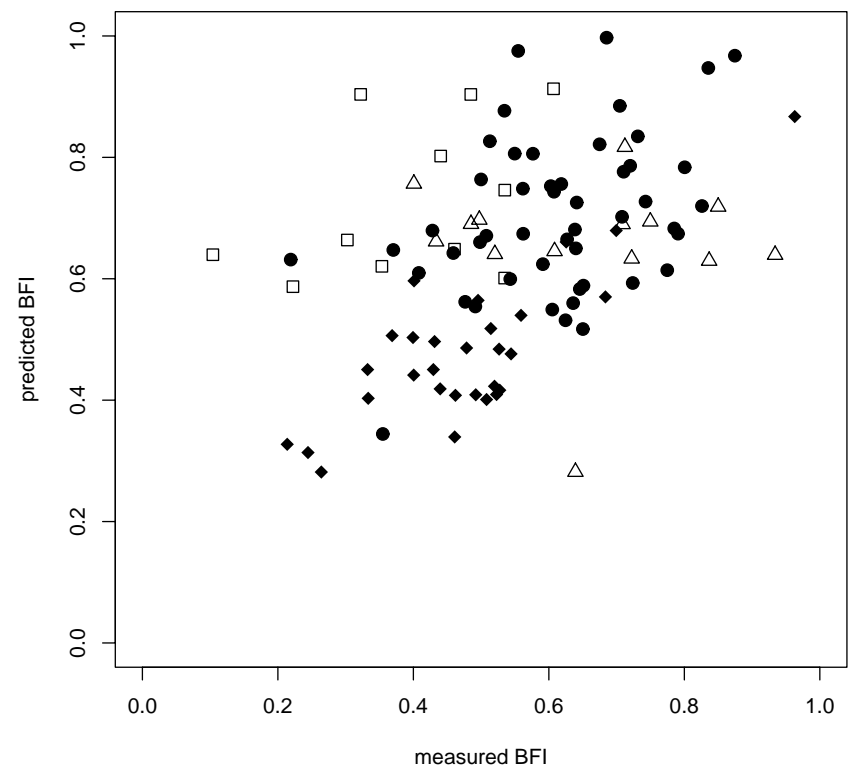

Fig. 3. Prediction of the BFI in 103 European catchments clustered into four groups: Triangles: Catchments governed by major artificial influences, large lake fractions, subsurface water sources or extreme climatic conditions (Group A); Squares: Catchments whose coefficient of variation of the annual BFI was larger than 0.18 (Group B); Rhomboids: Catchments in England and Wales (Group C); Circles: Remaining catchments outside England and Wales (Group D).

are situated predominantly in riverbeds, and some other scattered, mainly secondary classes were underestimated and large-area classes such as classes 17 and 24 on slowly permeable or inpermeable substrate were overestimated by the reclassification (Table 2 ).

The $\mathrm{NR}_{1: 1}$ as a quantitative measure also showed that the spatial agreement between original and reclassified map was generally good for classes with high coverage (Table 2). This confirms the impression of a good agreement from Fig. 1. However, there are exceptions such as classes 4 and 6, which are often encountered as a secondary class in the original map and therefore difficult to represent using the SGDBE.

Despite the insufficient information to distinguish different peat substrates in the SGDBE, there was a relatively good match for the aggregated class 29 , both with respect to coverage as well as spatial association. This was not the case for the other peat soil classes $(11,12,15,26,27)$, which showed considerable disagreement due to the missing peat information in the SGDBE. Peat class 15 on permeable substrate was also strongly underestimated because rocks and schists were classified as slowly permeable into physical setting iii) and peat soils on these substrates were thus attributed to peat class 27 .

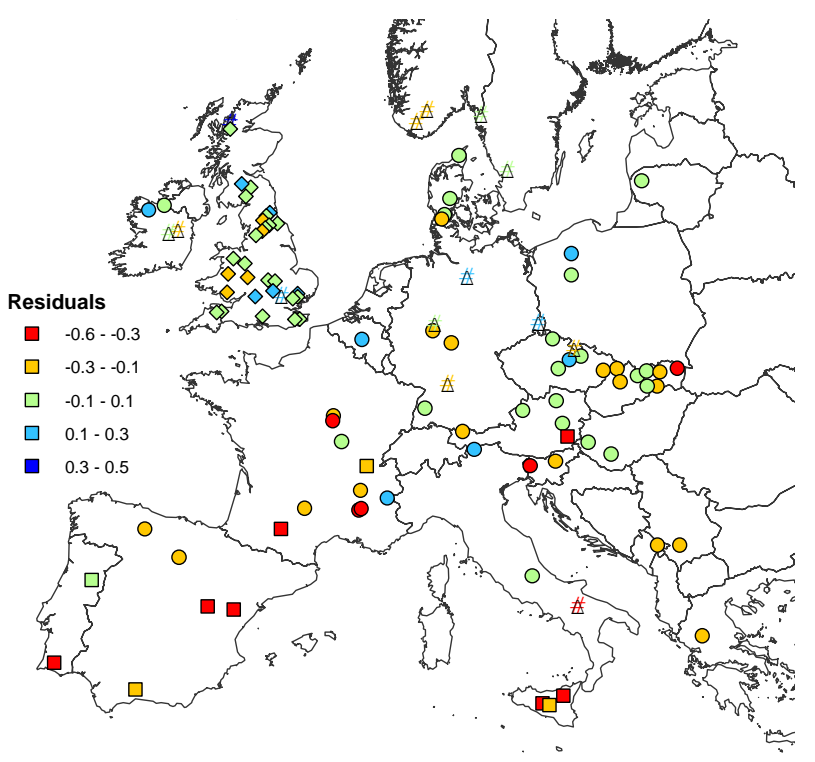

Fig. 4. Geographical location, group association (symbols) and residuals of the BFI predictions (colors) for the 103 catchments evaluated in the study. Residuals were obtained by comparing BFI values calculated from discharge data with prediction based on the reclassified SGDBE and regression coefficients as estimated by Boorman et al. (1995). Symbols are similar to Fig. 3: Triangles: catchments governed by major artificial influences (Group A); Squares: catchments with CV of annual BFI > 0.18 (Group B); Rhomboids: remaining catchments in England and Wales (Group C); Circles: remaining catchments outside England and Wales (Group D).

\subsection{HOST map extrapolated to Europe}

Based on the good performance of the reclassification for England and Wales, the HOST system was extrapolated to the rest of Europe (Fig. 2). When comparing the maps for England and Wales and the rest of Europe, a general trend towards a higher coverage of permeable classes is apparent, visually (Fig. 2) as well as quantitatively (Table 2). Classes with no impermeable or gleyed layers within $100 \mathrm{~cm}$ soil depth had higher coverages in Europe than in England and Wales, especially classes 2, 6 and 16 (Table 2). Also class 8 (soils with groundwater or aquifer present within $2 \mathrm{~m}$ depth but without impermeable or gleyed layers within $40 \mathrm{~cm}$ ) was more abundant in Europe than in England and Wales. This trend can also been seen by just comparing the most abundant classes (Table 2). In England and Wales, more than $30 \%$ of the soils were classified into classes 24 and 25, whereas more than $30 \%$ of the soils in Europe fell into classes 16 and 17. Two main problems were encountered during the extrapolation to Europe. First, the hydrological interpretation of parent materials in the SGDBE was not always clear. For example, a whole range of crystalline rocks and migmatites may be hard and impermeable (Table 1, physical subsetting iii.2) 


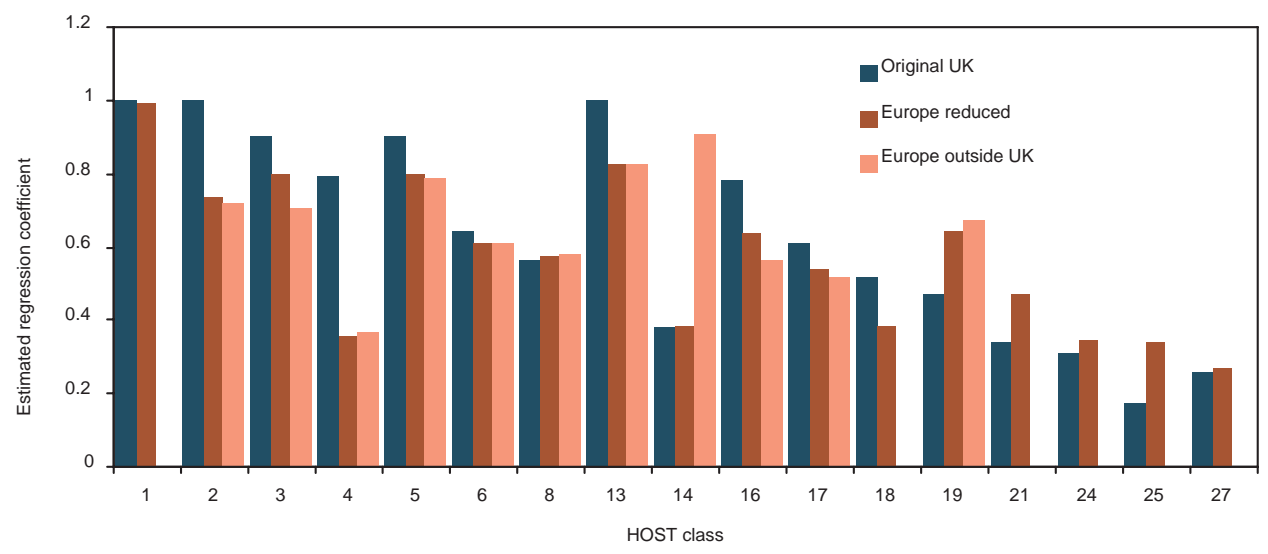

Fig. 5. Comparison of estimated regression coefficients per HOST class from the original UK study and from European catchments inside and outside the UK based on the reclassified SGDBE. Original UK designates the coefficients obtained by Boorman et al. (1995: Table 3.8). Europe reduced are the estimates for the reduced set of catchments from the UK and Europe (Groups C + D; rhomboids and circles in Figs. 3 and 4), constraint to lay between 0 and 1 and optimised using step-wise Akaike. Europe outside UK designates the values estimated from catchments outside the UK only (Group D; circles in Figs. 3 and 4), using constraints 0 and 1 and step-wise optimisation. Only those classes are shown for which coefficients from the Europe reduced dataset could be obtained.

or slightly porous and permeable (physical subsetting i.4) if they are weathered. Information on the state of weathering is completely missing in the SGDBE. Second, the resolution of the SGDBE is not homogeneous throughout Europe and 1:1 million describes the smallest printable object of the map. Some countries, e.g. Sweden or Spain are separated in only few large polygons and wide areas are attributed to the same HOST class. This is especially striking in the coverage of class 16 throughout Northern Sweden (Fig. 2).

3.3 Predicted BFIs using original UK regression coefficients

For 103 catchments in Europe, BFI values were predicted based on regression coefficients from the original UK estimation (Boorman et al., 1995) and compared to BFI values derived from river discharge measurements (Fig. 3). The dataset was separated into four groups (A-D).

A A total of 13 catchments were identified where the runoff regimes were governed by major artificial influences or large lake fractions, subsurface water sources or extreme climatic conditions (Figs. 3 and 4, triangles). These catchments were excluded from further analysis together with two more catchments with insufficient flow data. The $\mathrm{R}^{2}$ for the 88 remaining catchments was 0.256 .

B BFIs were over-predicted in a considerable number of the remaining catchments. It was found that absolute residuals of the BFI prediction correlated strongly with the coefficient of variation $(\mathrm{CV})$ of the yearly BFI $(r=0.53)$. In 11 catchments (Figs. 3 and 4, squares) the
$\mathrm{CV}$ of the annual BFI was higher than the maximum $\mathrm{CV}$ of yearly BFI in the available UK catchments (Group C) of 0.18. All these catchments were located in Southern Europe (Fig. 4).

C In the 29 catchments in the UK (Figs. 3 and 4, rhomboids) the reclassified SGDBE explained $68 \%$ of the variability in measured BFI. This is in agreement with the $79 \%$ explained by the original HOST classification (Boorman et al., 1995).

D Even without the catchments with a high CV of annual BFI, the predictability of BFI for the remaining 48 catchments outside the UK (Figs. 3 and 4, circles) was still relatively low $\left(\mathrm{R}^{2}=0.16\right)$.

The geographic distribution of residuals revealed a decreasing predictability of BFI from North to South (Fig. 4). Most catchments in Southern Europe had large negative residuals and a high variation in annual BFI. Of all the catchment properties included in the analysis, the mean topographic index explained the highest share of the remaining variation in BFI in the 48 catchments of group $\mathrm{D}(\mathrm{r}=0.32)$. Low mean topographic indices generally corresponded to over-predicted BFIs, while the residuals of the prediction decreased with larger mean topographic indices (data not shown).

\subsection{Estimated regression coefficients based on European catchments}

There was a good qualitative agreement between the regession coefficients estimated by the original UK study (Fig. 5: Original UK) and the estimates based on discharge data of 
the catchments in groups C and D (Fig. 5: Europe reduced). We mean by a good qualitative agreement that most regression coefficients estimated from the European data were consistent with their conceptual response models. For example, HOST classes on permeable substrate had higher regression coefficients than classes on impermeable substrate or with impermeable or gleyed layers. Class 16 on slowly permeable substrate had a higher regression coefficient than class 17 on impermeable substrate (Fig. 5). There was a notable exception: because class 19 is on less permeable substrate and class 21 on finer material than class 18, classes 19 and 21 should both have a lower regression coefficient than class 18 (Table 1).

As in the original UK study by Boorman et al. (1995), constraining the regression coefficients to values between 0 and 1 (the allowable range for the BFI) had only minor effects on the overall results. For easier readability of Fig. 5, only the constrained regression coefficients are shown.

Based on the good predictability of BFI in the UK from the original regression coefficients, we expected that including the UK catchments (Group C) into the estimation may draw coefficients towards the original values by Boorman et al. (1995). To test for this potential bias, a linear regression was fitted to the catchments outside the UK only (Group D). Using step-wise AIC produced coefficient estimates for 11 HOST classes (Fig. 5, Europe outside UK). With the exception of HOST class 14, the estimated regression coefficients were almost identical to the estimates including the UK catchments. This suggests that 10 out of 11 classes, which were estimable from non-UK catchments, were dominantly influenced by non-UK catchments, but the estimated regression coefficients were still close to those of Boorman et al. (1995).

In addition, there exists a general trend in the European regression coefficients: Except for the relatively small classes 14 and 19 (covering together less than $3 \%$ in the catchments, Table 2), regression coefficients for all HOST classes dominantly influenced by catchments outside the UK were estimated either lower or almost identical to the values by Boorman et al. (1995).

\section{Discussion}

The analysis of discharge data from selected European catchments has shown that (i) the information in the SGDBE is sufficient for a hydrological classification, (ii) the variability of BFI explained by soil classes tends to decrease from Northern to Southern Europe, probably because factors such as climate, vegetation and geomorphology, which are not reflected in the parameters originally used to differentiate HOST classes, have a greater influence on catchment response in Southern Europe, but (iii) there are no indications at this scale that the hydrological effect of a particular hydrological soil class would differ regionally.
4.1 The soil geographical database of Europe can be used as a basis for a hydrological classification

The process-based HOST classification was derived from the National Soil map of the UK at a scale of 1:250 000 (Boorman et al., 1995). Our study showed that the classification can be widely reproduced from the SGDBE at 1:1 million scale. Although both maps do have a limited amount of data in common, in that the STU attribute data in the SGDBE is based partly on data compiled for the 1:250000 National Soil Map of England \& Wales, the origin of their polygon boundaries is different and the range of soil types included in the SMU data for the SGDBE is considerably simplified compared to that used to derive the HOST map. Nevertheless, only a few attributes are missing in the SGDBE, mainly affecting the classification of peat soils, obviously because these are less important on a European scale. Also the integrated air capacity used to subdivide certain classes was difficult to represent. Comparing the reclassified SGDBE with the original HOST map shows that texture was a satisfactory proxy for soil water storage capacities in order to separate soils in HOST classes 18 to 23 (Table 2). Alternatively, the integrated air capacity may be derived using the pedotransfer functions available from HYPRES (Wösten et al. 1999).

Subdivisions are important for the goodness of fit of the estimated linear regression. The results by Boorman et al. (1995) show that there exist large differences between the estimated regression coefficients for a number of subdivided classes (e.g. 0.524 for class 20 and 0.218 for class 23 ). This suggests that a European classification may be greatly improved by subdividing large classes according to adequate criteria.

More critical in a Europe-wide classification are uncertainties in the hydrological interpretation of parent materials and the complete absence of certain situations in the HOST system. It was noticed that information on the state of weathering of parent material is important but not available. The line of the last European glaciation might be used to separate zones where substrates are likely to be weathered but testing this assumption would go beyond the scope of this preliminary study. Another uncertainty is the hydrological characteristics of parent materials which are not found in the UK and are thus not considered in the original HOST system. It might be useful to evaluate the inclusion of additional HOST classes for e.g. volcanic soils in a refined European classification.

A further limitation of a European hydrological soil classification is the variable quality of the underlying pedological information, which is not homogenous for the whole SGDBE since the quality of available soil surveys strongly differs between countries (European Commission, 2005, 37). The UK has country-wide soil data of relatively high quality, but soil information is poorer in several other countries (e.g. in Switzerland) and this is reflected in the SGDBE. In the UK, most SMU contain several soil type units, but in 
Switzerland, for example, only one soil type unit is given per SMU. This may be one reason why the BFI predicted from the reclassified SGDBE explains only around $22 \%$ of the variance in measured BFI in 55 Swiss catchments (R. Siber, personal communication). In contrast, a fine-scale mapping of dominant runoff processes in a small Swiss catchment allowed good prediction of rainfall-runoff transformations (Schmocker-Fackel et al., 2007).

A final consideration with respect to HOST characterisation of the SGDBE is the uncertainty associated with the interpretation of its hydrological attributes. For example, there can be inconsistencies between the identified soil water regime information, interpreted depth to gleyed horizon information and the hydrological interpretation of information conveyed by pedological soil type. Such inconsistencies mean that there is significantly more uncertainty in using the SGDBE to derive HOST classes than using the original UK soil map data.

4.2 The importance of soil for the discharge dynamics is decreasing from Northern to Southern Europe but its hydrological effect does not change

Residuals of the prediction based on the regression coefficients from the original UK study (Boorman et al. 1995) were found to be smallest in catchments located in Northern Europe, especially on the British Isles and in North-Central Europe (Fig. 4). The residuals are larger in hillier regions further South and in the Mediterranean. This result may be attributable to the relatively good soil data in the UK and countries such as the Czech Republic, Slovakia, Austria and Hungary (European Commission, 2005, 37). However, soil information in Italy, Slovenia and Serbia is also of relatively good quality but there exist major deviations from the predicted BFI, probably because of influences of topography and altitude. Hence, similar climatic and topographic conditions rather than data quality determines the predictability of BFI.

In catchments in Central and Southern Europe, additional parameters may become important, especially topography, climate and geomorphology. The mean topographic index was found to explain the highest proportion of variation in the residuals, indicating some effects of topography on the discharge dynamics not captured by the HOST classes. Generally, low mean topographic indices corresponded to overpredicted BFIs, while the predictions were more accurate with larger mean topographic indices. Although the mean topographic index would preferably be calculated from a DEM with a resolution higher than $90 \mathrm{~m}$, it appears to be a promessing measure of catchment topography at the European scale. A low value is found in hilly catchments with pronounced topography where rain events cause more surface runoff than in flat regions with the same soil characteristics (Page et al., 2005). Topography was found to be the main determinant of water residence in some study catchments in the Western U.S. (McGuire et al., 2005).

In alpine and pre-alpine situations, the long-term average precipitation sum may be an important factor for the discharge dynamics. It was identified as the most important predictor of discharge dynamics in country-wide analyses in Austria (Merz et al., 2006) and in Switzerland (Rosi Siber, personal communication) and explained $62 \%$ of the BFI variation in 25 catchments in the Elbe River basin (Haberlandt et al., 2001). However, mean annual precipitation was not found to be a crucial factor for BFI prediction on a European scale. There was also no correlation between BFI and precipitation intensity but this may also be due to the quality and resolution of the precipitation data currently available at a European scale.

On the other hand, we found constant hydrological effects of HOST classes throughout Europe. This can be seen from the fact that (i) the regression coefficients estimated from European discharge date were qualitatively similar to those from Boorman et al. (1995), and that (ii) excluding UK catchments did not affect the regression coefficients for 10 out of 11 HOST classes, for which such comparison was possible (Fig. 5). Thus, there was no change in the hydrological effect of HOST classes itself but only in the influence on overall catchment response as summarized by the BFI. This points to the issue that, for our preliminary exercise, we validated a soil hydrological classification with catchment response, two measures that are not necessarily connected.

\subsection{The concept of a long-term BFI is breaking down in} Mediterranean catchments

Highest residuals of BFI prediction were found in Mediterranean catchments (Fig. 4) and may be explained by a number of factors: An important issue in Mediterranean catchments is water abstraction and deviation for irrigation agriculture and human consumption (Gasith and Resh, 1999). The discharge data was not corrected for water abstraction and may thus have been affected, but the phenomenon seems to be too systematic to be explained by this factor alone. In addition, the number of usable flow years was limited for some of the Mediterranean catchments (3 years as minimum) and this may also affect the predictability of a long-term BFI.

Another crucial factor for the lower predictability of discharge dynamics in Sourthern than in Northern Europe are differences in climate and subsequently in soil hydrology. The semi-arid climate in the Mediterranean is characterised by high interannual variability (Zveryaev, 2004) as well as intraannual variability, i.e. "rainfall events are few, short-lived and unreliable" (Puigdefabregas et al., 1995). Hence, subsurface soil layers are rarely saturated and water movement is mainly through infiltration-excess overland flow or unsaturated subsurface flow. Runoff produced on semi-arid hillsopes may reinfiltrate into unsaturated soil or cracks further downslope and be effectively disconnected from the main 
stream (Bergkamp, 1998). Hence, factors controlling infiltration, such as soil surface structure, the spatial distribution of residual water and the type of vegetation present, are crucial for the dynamics of the rainfall-runoff response and subsequently the BFI. Since these parameters were not considered in the present form of the classification, it is not surprising that residuals of BFI predictions from HOST were largest in Southern Europe (Fig. 4).

In order to predict the BFI from soil characteristics and hence the HOST classification alone, it is necessary that the soil is the primary driver of discharge dynamics in a catchment. The high variability in yearly BFI in most of the catchments located in Southern Europe suggests that variable factors such as precipitation play an importrant role. The intensity, length, spatial and temporal variability of rainfall events may interact with the presence of residual moisture and vegetation in complex manner and, hence, summarising discharge dynamics into a single long-term measure is likely to fail. Instead, statistics of individual discharge events should be analysed taking into account climatic conditions of the event, antecedent soil moisture, vegetation status as well as soil properties. For such purposes, a parameter taking into account precipitation and flow may be a better method for characterizing catchment response to rainfall. Such a measure is the Standard Percentage Runoff (SPR), the percentage of rainfall that causes the short-term increase of flow at the catchment outlet (Boorman et al., 1995).

4.4 Further steps needed towards a hydrological classification of European soils

This investigation is clearly of preliminary character and aimed at evaluating the feasibility of a European hydrological classification. It showed that the attributes available in the SGDBE are generally sufficient, but depend on the underlying soil information per country. To overcome this limitation, additional pedological and geological maps could, where available, be used to improve the hydrological interpretation. Also a number of classes could be added to the existing HOST classification relatively easily, if necessary.

Our evaluation has also shown that the number of 103 catchments used was rather small compared to the number of 27 HOST classes and that especially long-term flow records from the Mediteranean were lacking. The original HOST system (Boorman et al., 1995) used BFI values from nearly 600 catchments in the UK and Merz et al. (2006) analysed 337 catchments in Austria. Relating the discharge data to soil information required the delineation of catchments and this proved to be far more difficult than expected. For less than $50 \%$ of the gauging stations for which discharge data was available, it was possible to delineate the catchment with sufficient accuracy and confidence. This calls for a joint multi-national action in collecting a database of gauging stations with high-quality discharge and precipitation data and precise coordinates in order that the catchment can be de- lineated. Such a database would allow the necessary evaluation of potential uncertainties in the classification and of potential improvements through subdivisions and additional HOST classes.

The limited usefulness of the BFI concept under Mediterranean conditions suggests that event-based measures such as SPR may be more flexible to incorporate effects of variable precipitation and vegetation. Testing a refined soil classification including information on vegetation and soil surface structure against an event-based measure of runoff response to rainfall may provide an integrated view on catchment hydrology at the European scale.

Ultimately, a hydrological classification of European soils may assist decisions at a multi-national or European level and may be useful in predicting discharge behaviour in ungauged catchments (Soulsby et al., 2006a). Because the processes of water flow through soil are incorporated in the classification, it may be the basis for models with few parameters (e.g. Maréchal and Holman, 2005), which can be usefully applied to model changes in climatic conditions or land-use (Kirchner, 2006).

An understanding of the hydrological mechanisms and transport pathways of rainfall to surface waters at the catchment level is of critical importance in managing the quality and quantity of European water resources and is fundamental to implementing the European Water Framework Directive. Development of a robust hydrological classification of European soils would provide such an understanding and it should be in the interests of legislators, managers and research scientists to work together to achieve this goal.

Acknowledgements. We thank K. Abbaspour, M. Amini, M. Frey, C. Leu and R. Siber and three anonymous reviewers for helpful comments on the manuscript. The Global Runoff Data Centre, the European Soil Bureau and the National Soil Resources Institute are acknowledged for making their data available for this study, which was funded by the EU Sixth Framework program through the project ERAPharm, Environmental Risk Assessment of Pharmaceuticals (Contract No. SSPI-CT-2003-511135).

Edited by: E. Zehe

\section{References}

Bergkamp, G.: A hierarchical view of the interactions of runoff and infiltration with vegetation and microtopography in semiarid shrublands, Catena, 33, 201-220, 1998.

Beven, K. J.: Rainfall-runoff modelling, J. Wiley \& Sons, Chichester, 2001.

Blanchard, P. E. and Lerch, R. N.: Watershed vulnerability to losses of agricultural chemicals: Interactions of chemistry, hydrology, and land-use, Environ. Sci. Technol., 34, 3315-3322, 2000.

Boorman, D. B., Hollis, J. M., and Lilly A.: Hydrology of soil types: a hydrologically-based classification of the soils of the United Kingdom, Inst. Hydrol., Wallingford, http://www.ceh.ac. uk/products/publications/hydrology.html, 1995. 
CEC: Soil Map of the European Communities at scale 1:1,000,000, Office Off. Publ. Eur. Comm., Luxembourg, 1985.

Dunn, S. M. and Lilly, A.: Investigating the relationship between a soils classification and the spatial parameters of a conceptual catchment-scale hydrological model, J. Hydrol., 252, 157-173, 2001.

European Commission: Soil Atlas of Europe, Office Off. Publ. Eur. Comm., Luxembourg, 2005.

Gasith, A. and Resh, V. H.: Streams in Mediterranean climate regions: Abiotic influences and biotic responses to predictable seasonal events, Annu. Rev. Ecol. Systematics, 30, 51-81, 1999.

Haberlandt, U., Klocking, B., Krysanova, V., and Becker, A.: Regionalisation of the base flow index from dynamically simulated flow components - a case study in the Elbe River Basin, J. Hydrol., 248, 35-53, 2001.

Hewlett J. D. and Hibbert, A. R.: Factors affecting the response of small watersheds to precipitation in humid areas, edited by: Sopper, W. E., Lull, H. W., Forest Hydrology, Pergamon Press, New York, 275-290, 1967.

Hollis, J. M., Jones, R. J. A., Marshall, C. J., Holden, A., Van de Veen, J. R., and Montanarella, L.: SPADE-2: The soil profile analytical database for Europe, version 1.0. European Soil Bureau Research Report No.19, EUR 22127 EN, Office Off. Publ. Eur. Comm., Luxembourg, 2006.

Hollis, J. M. and Woods, S. M.: The measurement and estimation of saturated soil hydraulic conductivity, SSLRC report to MAFF, Soil Surv. Land Res. Centre, Silsoe, 1989.

Institute of Hydrology: Low Flow Studies, Inst. Hydrol., Wallingford, 1980.

King, D., Daroussin, J., and Tavernier, R.: Development of a soil geographical database from the soil map of the European Communities, Catena, 21, 37-56, 1994.

Kirchner, J. W.: Getting the right answers for the right reasons: Linking measurements, analyses, and models to advance the science of hydrology, Water Resour. Res., 42, W03S04, 2006.

Lacey, G. C. and Grayson, R. B.: Relating baseflow to catchments properties in south-eastern Australia, J. Hydrol., 204, 231-250, 1998.

Leu, C., Singer, H., Stamm, C., Müller, S. R., and Schwarzenbach, R. P.: Variability of herbicide losses from 13 fields to surface water within a small catchment after a controlled herbicide application, Environ. Sci. Technol., 38, 3835-3841, 2004.

Lin, H., Bouma, J., Pachepsky, Y., Western, A., Thompson, J., Van Genuchten, R., Vogel, H. J., and Lilly, A.: Hydropedology: Synergistic integration of pedology and hydrology, Water Resour. Res., 42, W05301, 2006.

Maréchal, D. and Holman, I. P.: Development and application of a soil classification-based conceptual catchment-scale hydrological model, J. Hydrol., 312, 277-293, 2005.

McDonnell, J. J.: Where does water go when it rains? Moving beyond the variable source area concept of rainfall-runoff response, Hydrol. Process., 17, 1869-1875, 2003.
McDonnell, J. J. and Woods, R.: On the need for catchment classification, J. Hydrol., 299, 2-3, 2004.

McGuire, K. J., McDonnell, J. J., Weiler, M., Kendall, C., McGlynn, B. L., Welker, J. M., and Seibert, J.: The role of topography on catchment-scale water residence time, Water Resour. Res., 41, W05002, 2005.

Merz, R., Blöschl, G., and Parajka, J.: Spatio-temporal variability of event runoff coefficients, J. Hydrol., 331, 591-604, 2006.

New, M., Lister, D., Hulme, M., and Makin, I.: A high-resolution data set of surface climate over global land areas, Clim. Res., 21, $1-25,2002$.

O'Callaghan, J. and Mark, D.: The extraction of drainage networks from digital elevation data, Comput. Vision Graph., 28, 328-344, 1984.

Page, T., Haygarth, P. M., Beven, K. J., Joynes, A., Butler, T., Keeler, C., Freer, J., Owens, P. N., and Wood, G. A.: Spatial variability of soil phosphorus in relation to the topographic index and critical source areas: Sampling for assessing risk to water quality, J. Environ. Qual., 34, 2263-2277, 2005.

Puigdefabregas, J., del Barrio, G., Boer, M. M., Gutiérrez, L., and Solé, A.: Differential responses of hillslope and channer elements to rainfall events in a semi-arid area, Geomorphology, 23, 337-351, 1998.

R Development Core Team R: A language and environment for statistical computing, R Found. Stat. Comput., Vienna, Austria, 2006.

Schmocker-Fackel, P., Naef, F., and Scherrer, S.: Identifying runoff processes on the plot and catchment scale, Hydrol. Earth Syst. Sci., 11, 891-906, 2007, http://www.hydrol-earth-syst-sci.net/11/891/2007/.

Schneider, M. K., Stamm, C., and Fenner, K.: Selecting scenarios to assess exposure of surface waters to veterinary medicines in Europe, Environ. Sci. Technol., 41, 4669-4676, 2007.

Sivapalan, M.: Prediction in ungauged basins: a grand challenge for theoretical hydrology, Hydrol. Process., 17, 3163-3170, 2003.

Soil Conservation Service: SCS National Engineering Handbook, Sect. 4, Hydrology, U.S Dept. Agr., Washington D.C., 1972.

Soulsby, C., Tetzlaff, D., Dunn, S. M., and Waldron, S.: Scaling up and out in runoff process understanding: insights from nested experimental catchment studies, Hydrol. Process., 20, 2461-2465, 2006a.

Soulsby, C., Tetzlaff, D., Rodgers, P., Dunn, S., and Waldron, S.: Runoff processes, stream water residence times and controlling landscape characteristics in a mesoscale catchment: An initial evaluation, J. Hydrol., 325, 197-221, 2006b.

Wösten, J. H. M., Lilly, A., Nemes, A., and Le Bas, C.: Development and use of a database of hydraulic properties of European soils, Geoderma, 90, 169-185, 1999.

Zveryaev, I. I.: Seasonality in precipitation variability over Europe, J. Geophys. Res., Atmos., 109, Art. No. D05103, 2004. 